\title{
Unintended Electrical Shock
}

National Cancer Institute

\section{Source}

National Cancer Institute. Unintended Electrical Shock. NCI Thesaurus. Code C133527.

The device delivers unintended electrical shock. 